\title{
L2- AND L1-NORM APPLIED TO INVERSION OF NONHYPERBOLIC TRAVEL-TIME
}

\author{
Nelson Ricardo Coelho Flores Zuniga ${ }^{1}$, Fernando Brenha Ribeiro ${ }^{1}$ and Viacheslav Ivanovich Priimenko ${ }^{2}$
}

ABSTRACT. Several nonhyperbolic multiparametric travel-time approximations were tested to perform the velocity analysis in the last decade. The previous works studied not only the accuracy but also the complexity concerning the topology of the objective function and the statistical distribution. However, the variation of the norm was poorly studied. As some approximations presented very good results, it is important to understand the behavior of the application of the L1-norm rather than the L2-norm. Therefore, it was selected an approximation which showed the best set of results so far. Thus, this approximation was compared to the L2- and L1-norm aiming to observe its behavior for a PP and a PS reflection event. With this set of information, it is possible to evaluate what kind of improvement the L1-norm can bring for this kind of analysis.

Keywords: objective function, nonhyperbolic, probability distribution.

RESUMO. Diversas aproximações não-hiperbólicas multiparamétricas de tempos de trânsito foram testadas para realizar a análise de velocidades na última década. Trabalhos anteriores estudaram não apenas a precisão, mas também a complexidade de topologia da função objetivo e a distribuição estatística destas aproximações. Entretanto, a variação de norma foi pouco estudada. Como algumas aproximações apresentaram resultados muito bons, é importante entender o comportamento da aplicação da norma L1 ao invés da L2. Portanto, foi selecionada uma aproximação que apresentou o melhor conjunto de resultados até o momento. Dessa forma, esta aproximação foi comparada com as normas L2 e L1, visando observar seu comportamento para eventos de reflexão PP e PS. Com esse conjunto de informações, é possível avaliar que tipo de melhoria a aplicação da norma L1 pode trazer para este tipo de análise.

Palavras-chave: função objetivo, não-hiperbólica, distribuição probabilística.

\footnotetext{
${ }^{1}$ Universidade de São Paulo, Instituto de Astronomia, Geofísica e Ciências Atmosféricas (IAG-USP), Departamento de Geofísica. Rua do Matão 1226 - Cidade Universitária - 05508-090, São Paulo, SP, Brazil. Phone: +55(11) 3091-4755 - E-mails: nelson.zuniga@iag.usp.br; fernando.brenha@iag.usp.br 2Universidade Estadual do Norte Fluminense (UENF), Laboratório de Engenharia e Exploração de Petróleo (LENEP), Avenida Brennand s/n - Imboacica - 27910-970, Macaé, RJ, Brazil. Phone: +55(22) 2765-6565 - E-mail: slava@lenep.uenf.br
} 


\section{INTRODUCTION}

For several problems in signal processing the L2-norm is used, once the least squares error approximate solution is preferred for this kind of tasks. However, the L1-norm can be preferable in many situations, due to the fact that a complex topology of objective function with small distortions can be attenuated with the least absolute deviation (Khaleelulla, 1982; Bourbaki, 1987).

In seismic processing, some events can result in a very complex topology of the objective function, once the large offsets with layered media, the converted PS waves and the use of OBN (Ocean Bottom Nodes) data cause a strong nonhyperbolicity to the reflection event. The velocity analysis suffers significantly with this problem while the inversion procedure is being performed. Many approximations were developed in the last decades (e.g. Malovichko, 1978; Muir \& Dellinger, 1985; Slotboom, 1990; Alkhalifah \& Tsvanki, 1995; Li \& Yuan, 2001; Ursin \& Stovas, 2006; Blias, 2009) to deal with the different causes of the nonhyperbolicity with different parameters and different complexities.

Recent works (e.g. Zuniga et al., 2015, 2016a,b, 2017; Zuniga, 2017) showed not only the accuracy comparison among these nonhyperbolic approximations, but also the complexity analysis study concerning the objective function. This kind of test was important to understand the behavior of each approximation related to their statistical distributions. It was observed that some approximations showed always a multimodal behavior with a global and one or more local minimum regions (e.g. Muir \& Dellinger, 1985; Li \& Yuan, 2001), some always presented a unimodal behavior with only the global minimum region (e.g. Malovichko, 1978; Slotboom, 1990; Alkhalifah \& Tsvanki, 1995), and others both behavior varying with the model (e.g. Ursin \& Stovas, 2006; Blias, 2009), as observed by Zuniga et al. (2018).

As the use of the L1-norm can attenuate and even suppress the local minimum regions or subtle features, it is important to understand what kind of improvement in can be obtained. As the approximation proposed by Li \& Yuan (2001) showed the best results in recent works concerning the accuracy, it was selected to be tested to understand if even a nonhyperbolic approximation with a complex topology of the objective function can have its results significantly improved with the L1-norm.

It is possible to compute the relative errors between the calculated curves with the nonhyperbolic multiparametric approximation and the observed curve of the reflection events of the chosen Model. The RFM (Residual Function Maps) can be used to study the structure of the objective function aiming to analyze the complexity of its topology. The accuracy analysis can be performed with the Li \& Yuan (2001) approximation for the conventional wave reflection event (PP) and the converted wave event (PS) and for both L2- and L1-norm. Thus, it is possible to find whether the L1-norm can provide more reliable results during the travel-time curves inversion.

\section{OFFSHORE MODEL STUDIED}

In the Table 1, presents the parameters of the Model used for this study. This Model is an offshore layered model with a carbonate reservoir $\left(V_{P}=4010 \mathrm{~m} / \mathrm{s}\right.$ and $\left.V_{S}=2012 \mathrm{~m} / \mathrm{s}\right)$. It is sealed by a salt structure composed by the $3^{\text {rd }}, 4^{\text {th }}$ and $5^{\text {th }}$ layers.

The salt structure can be more easily observed in Figure 1, where the variations of the physical properties are shown.

In Figure 2, it is possible to observe the ray tracing generated by a simulation with parameters of the Model. The travel-time curves of the PP reflection event and the PS reflection event were generated (Margrave, 2000, 2003; Thorbecke \& Draganov, 2012).

Table 1 - The parameters of the Model: Layer thickness $(\Delta \mathrm{z})$, P-wave velocity $\left(V_{P}\right)$, S-wave velocity $\left(V_{S}\right)$ and $V_{P} N_{S}$ ratio

\begin{tabular}{|c|c|c|c|c|}
\hline Layer & $\begin{array}{c}\Delta \mathbf{z} \\
(\mathbf{m})\end{array}$ & $\begin{array}{c}\boldsymbol{V}_{\boldsymbol{P}} \\
(\mathbf{m} / \mathbf{s})\end{array}$ & $\begin{array}{c}\boldsymbol{V}_{\boldsymbol{s}} \\
(\mathbf{m} / \mathbf{s})\end{array}$ & $\boldsymbol{V}_{\boldsymbol{P}} / \boldsymbol{V}_{\boldsymbol{s}}$ \\
\hline Water & 2157 & 1500 & 0 & - \\
1 & 496 & 2875 & 1200 & 2.40 \\
2 & 108 & 3505 & 1628 & 2.15 \\
3 & 664 & 4030 & 2190 & 1.84 \\
4 & 262 & 5005 & 2662 & 1.88 \\
5 & 1485 & 4220 & 2210 & 1.91 \\
\hline
\end{tabular}

\section{NONHYPERBOLIC MULTIPARAMETRIC TRAVEL-TIME APPROXIMATION}

The Equation 1, the approximation proposed by Li \& Yuan (2001), has a nonhyperbolic parameter, the $\gamma$ parameter, previously studied by Li \& Yuan (1999), and based on the anisotropic parameters of Thomsen (1986). This approximation considers the CP (Conversion Point) aiming to control the effects of a 


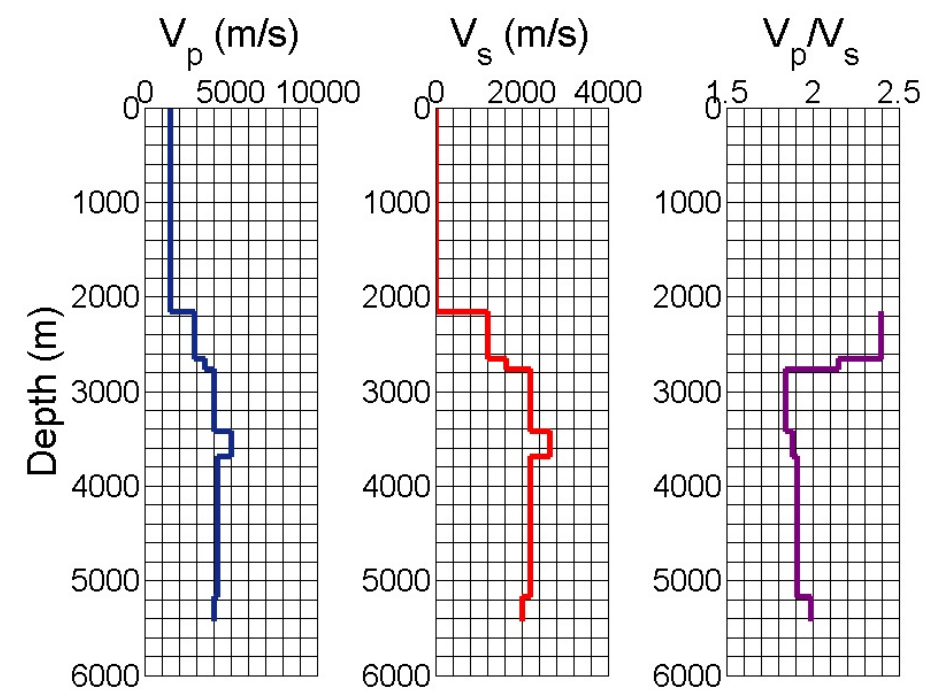

Figure 1 - P-wave velocity $\left(V_{P}\right)$, S-wave velocity $\left(V_{S}\right)$ and $V_{P} N_{S}$ ratio profiles of the Model.
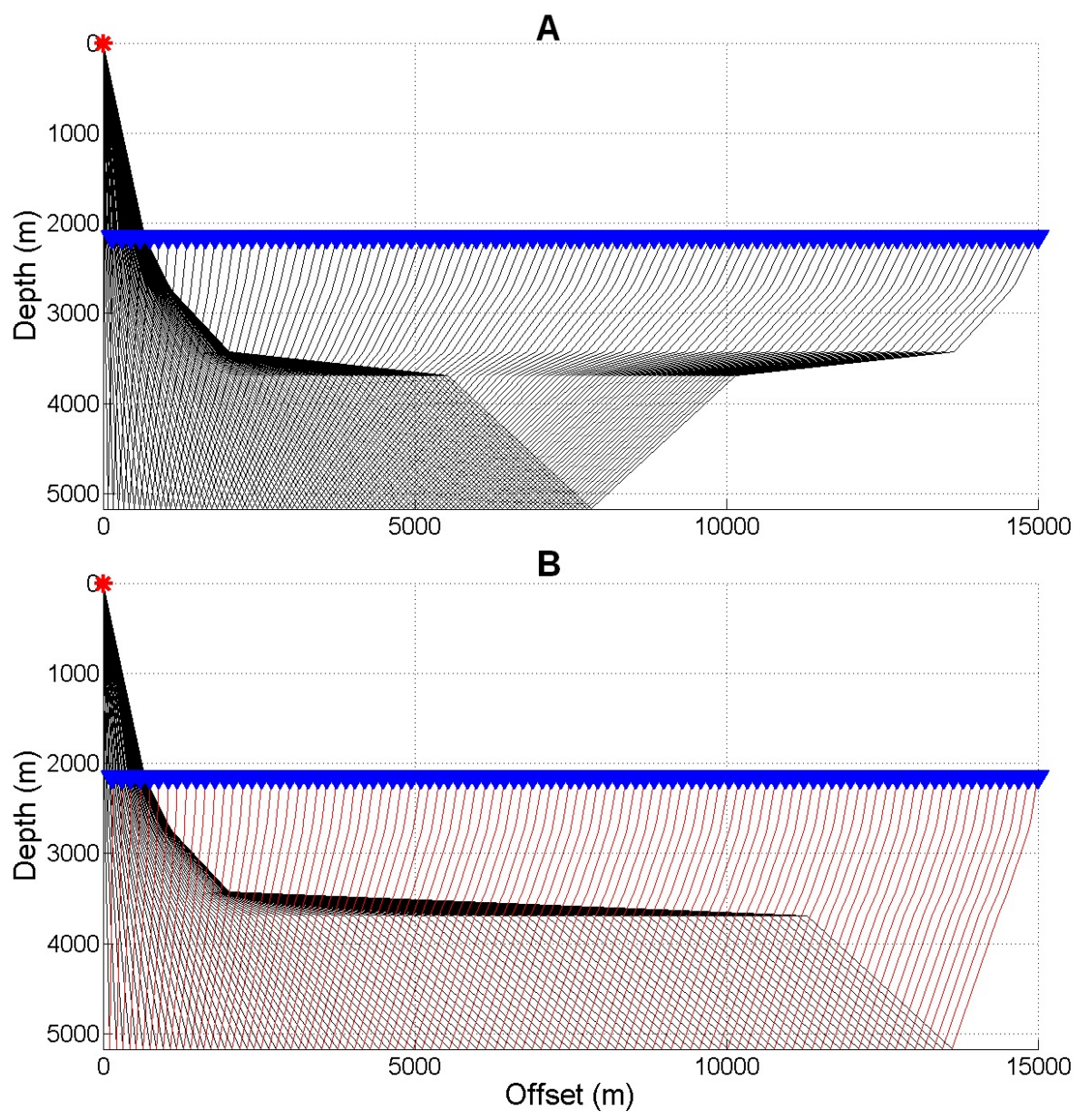

Figure 2 - Ray tracing of the (A) PP wave reflection event and (B) PS wave reflection event of the Model. 
nonhyperbolicity associated to the wave conversion joint to large offsets for layered media.

$$
t=\sqrt{t_{0}^{2}+\frac{x^{2}}{v^{2}}-\frac{(\gamma-1)}{\gamma v^{2}} \frac{(\gamma-1) x^{4}}{4 t_{0}^{2} v^{2}+(\gamma-1) x^{2}}}
$$

Where $\gamma$ is the ratio between the squared P-wave stacking velocity $v_{P 2}$ and the squared converted wave stacking velocity $v_{C 2}$ (Eq. 2).

$$
\gamma=\frac{v_{P 2}^{2}}{v_{C 2}^{2}}=\frac{\gamma_{e f f}\left(1+\gamma_{0}\right)}{\left(1+\gamma_{e f f}\right)}
$$

The relation $\gamma_{\text {eff }}$ is expressed by $\gamma_{\text {eff }}=\gamma_{2}^{2} / \gamma_{0}$, where $\gamma_{2}$ is the ratio between the P-wave and S-wave stacking velocities, and $\gamma_{0}$ is the ratio between $\mathrm{P}$-wave velocity and S-wave velocity which travel along the normal component.

The approximation was lately studied concerning its parameter by Li (2003), and after compared with other approximations (Zuniga et al., 2015, 2016b, 2017; Zuniga, 2017). As the approximation showed to have a multimodal statistical distribution in previous works, it must be tested with the L1-norm rather than the L2-norm to observe if it could suppress the local minimum region, or at least makes a narrower global minimum region to increase the accuracy during the inversion.

\section{COMPLEXITY ANALYSIS OF THE OBJECTIVE FUNCTION FOR L2- AND L1-NORM}

The analysis of the objective function concerning its complexity can be performed by the use of residual function maps (RFM) aiming to study the complexity of the topology of an objective function (Larsen, 1999; Kurt, 2007).

In the case used here, the RFM represents the relation between the additional parameter and the RMS (root mean square) velocity of the event. The additional parameter is the $\gamma$ nonhyperbolic parameter, used in the approximation proposed by Li \& Yuan (2001). The third dimension of the hyperplane is the representation of the minimum values.

In mathematics, norm is the total length of a set of vectors in a vector space or the total size of a set of matrices in a matrix space. The norm is a function which assigns a strictly positive length of size to each vector in a vector space, being not valid to zero vector (and the same idea applied to matrices). The least squares method (L2-norm) is based on the sum of the square of the difference between the observed value and the estimated one. While the least absolute deviation (L1-norm), minimizes the sum of the absolute difference between the observed value and the estimated one.
In this work, the focus is to observe the variation of behavior between L2- and L1-norm for each reflection travel-time event (PP and PS) with the selected approximation.

In the Figure $3 \mathrm{~A}$, it is possible to observe a complex structure of the objective function, with the global minimum region and a local minimum one, with a significant variation between the maximum and the minimum regions. The variation of the structure alongside both axes is very similar, what shows a sensibility resembling between the velocity of the event and the nonhyperbolicity parameter. It is clearly observed that the $\gamma$ parameter must be always higher than 0 , and when this parameter is 1 , there is an inconsistency in the topology, due to the fact that when $\gamma=1$, the Li \& Yuan (2001) becomes the hyperbola equation (Dix, 1955). Thus, it can be suggested that the local minimum region of this approximation is associated to the transition of the hyperbolic behavior.

In the Figure 3B, the application of the L1-norm brought a very similar structure of the objective function, with no variation concerning the statistical distribution. However, the global minimum region and the local minimum region are apparently more correlated, and the most interesting observation is the narrower global minimum region, with a more abrupt structure, fact that is important to perform a more accurate and faster inversion.

For the PS converted event (Fig. 4), it is possible to observe in Figure $4 \mathrm{~A}$, a structure similar to the Figure $3 \mathrm{~A}$, however with a displacement of the structure associated to the variation of the set of parameters, what was already observed in previous works. However, the characteristics of the structure are very similar to the PP reflection event.

Concerning the application of the L1-norm for this event (Fig. 4B), there is a more related local and global minimum region, but not so strong as the one showed by the conventional event. However, a more abrupt structure with a narrower global minimum region and a multimodal statistical distribution are observed, similarly to the conventional event.

\section{ACCURACY ANALYSIS}

To compare nonhyperbolic travel-time approximations was an important analysis to understand which approximation presents the best results and is the most reliable to perform a travel-time curve inversion procedure. This kind of comparison has been performed during the last decade (Aleixo \& Schleicher, 2010; Golikov \& Stovas, 2012; Zuniga et al., 2015, 2016a,b, 2017; Zuniga, 2017). As the recent works showed an extremely positive 


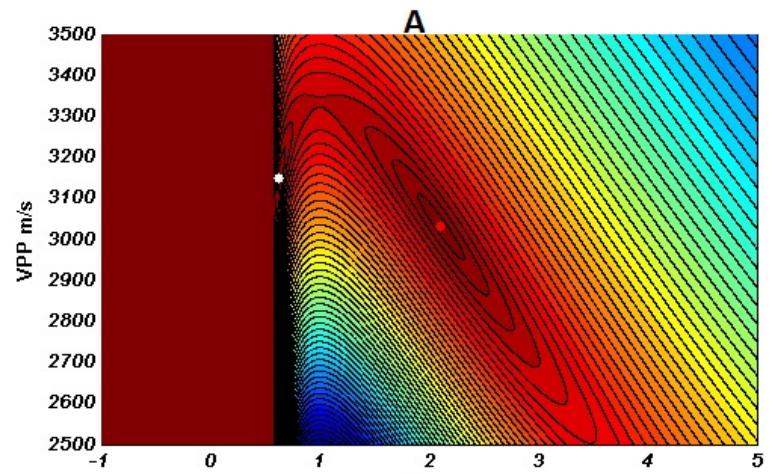

B

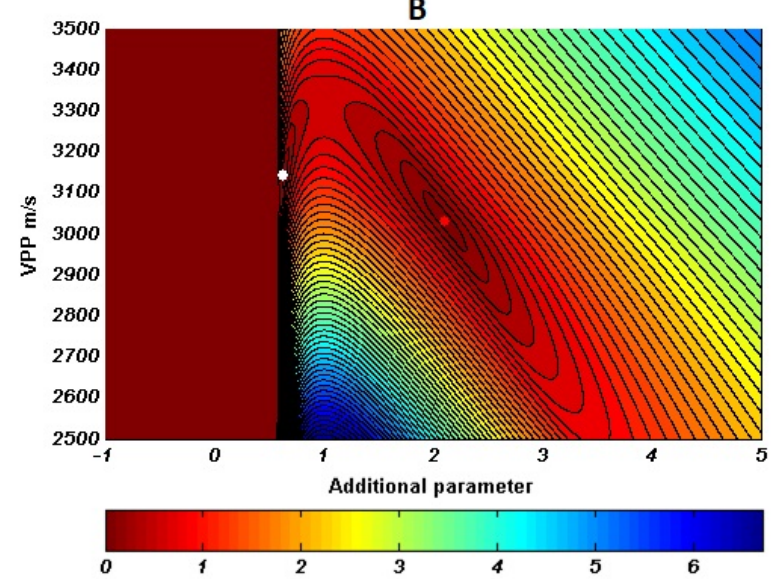

Figure 3 - Residual function maps to demonstrate the complexity of the approximation proposed by Li \& Yuan (2001) for the PP wave reflection event with (A) L2-norm and (B) L1-norm. Red dispersions represent the global minimum region and the white dispersions represent the local minimum region.

results with the use of the approximation proposed by Li \& Yuan (2001), the accuracy analysis of this equation is important to be performed concerning the L1-norm, once there is no previous works with this kind of tests.

After calculate the difference between the calculated curve with the selected approximation and the observed curve, the errors must be computed and compared for both reflection events and both norms.

For the PP wave reflection event, it is possible to observe that (as it was expected) the errors are significantly lower than the error for the converted wave reflection event (Fig. 5). However, the most important observation is concerning the comparison of the L2- and L1-norm, where it is possible to observe that for the PP reflection event, the L1-norm presents a lower error than the L2-norm. For the PS event, it is possible to observe the same behavior even with a more significantly lower error after the application of the L1-norm. Then, the L1-norm showed to be

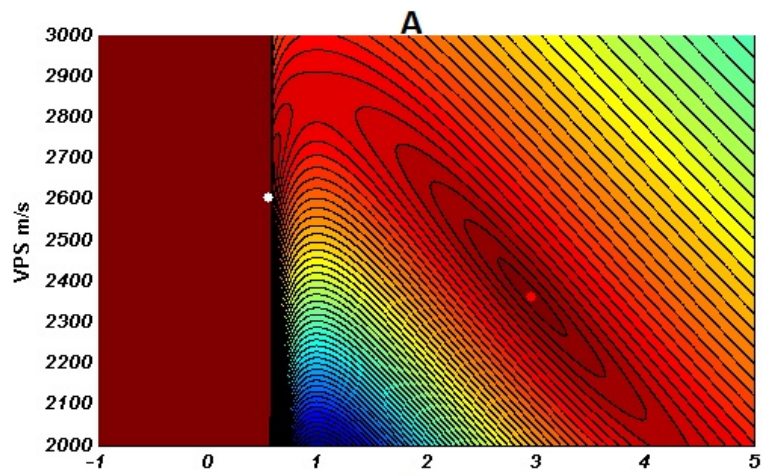

B

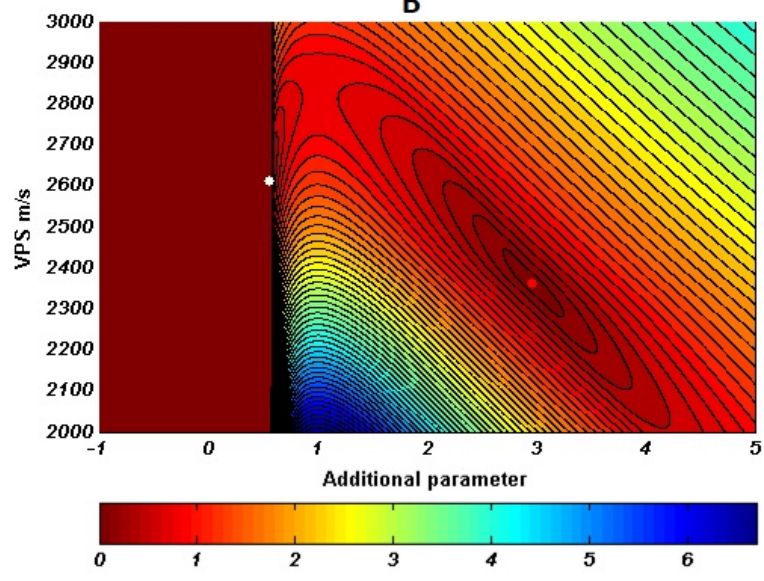

Figure 4 - Residual function maps to demonstrate the complexity of the approximation proposed by Li \& Yuan (2001) for the PS wave reflection event with (A) L2-norm and (B) L1-norm. Red dispersions represent the global minimum region and the white dispersions represent the local minimum region.

more efficient than the L2-norm for this kind of problem with a processing time 16\% lower for the PP event and 17\% lower for the converted event.

\section{CONCLUSIONS}

The approximation proposed by Li \& Yuan (2001) showed a better result after the application of the L1-norm for PP and the PS reflection events. The narrower global minimum region and the more abrupt structure of the objective function were the most important improvements of the L1-norm rather than the L2-norm.

There was a significant improvement for both reflection events concerning the accuracy, and even with no difference of statistical distribution, the results are clearly more precise with the L1-norm.

So, even for an always multimodal approximation, the application of the least absolute deviation rather than the least 


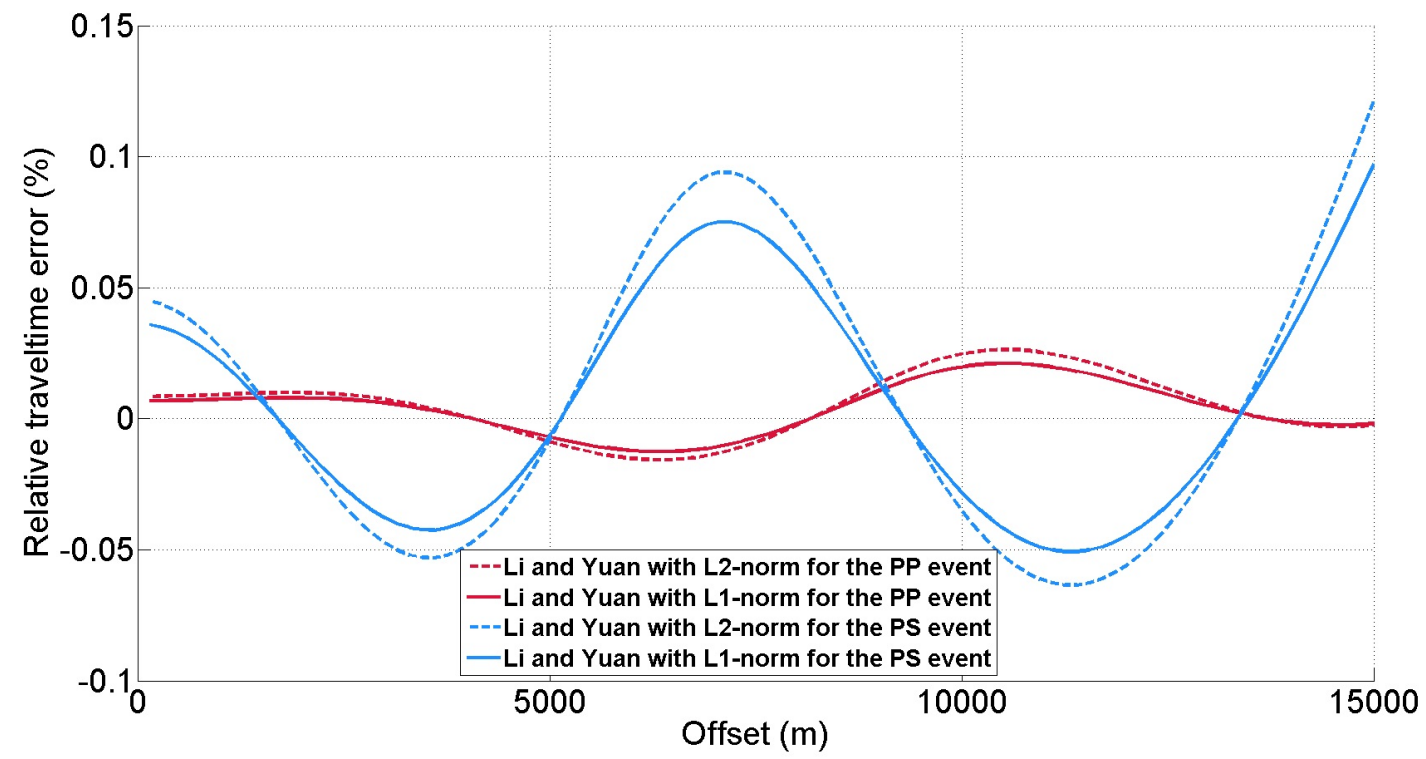

Figure 5 - Relative errors in travel-time between the observed curve and the calculated curve with the Li \& Yuan (2001) approximation for each norm and for PP wave reflection event and PS wave reflection event.

squares presented a strong enhance in the quality of the parameters recovery, with more accurate results.

\section{ACKNOWLEDGEMENTS}

This study was financed in part by the Coordenação de Aperfeiçoamento de Pessoal de Nível Superior - Brazil (CAPES) - Finance Code 001. This study was financed in part by the Conselho Nacional de Desenvolvimento Científico e Tecnológico - Brazil (CNPq).

\section{REFERENCES}

ALEIXO R \& SCHLEICHER J. 2010. Traveltime approximations for q-P waves in vertical transversely isotropic media. Geophysical Prospecting, 58: 191-201.

ALKHALIFAH T \& TSVANKI I. 1995. Velocity analysis for transversely isotropic Media. Geophysics, 60: 1550-1566.

BLIAS E. 2009. Long-offset NMO approximations for a layered VTI model: Model study. In: 79th Annual International Meeting. Expanded Abstract, p. 3745-3749. Houston, TX, USA: Society of Exploration Geophysicists.

BOURBAKI N. 1987. Topological vector spaces. Springer-Verlag Berlin and Heidelberg. $362 \mathrm{pp}$.

DIX C. 1955. Seismic velocities from surface measurements. Geophysics, 20: 68-86.
GOLIKOV P \& STOVAS A. 2012. Accuracy comparison of nonhyperbolic moveout approximations for qP-waves in VTI media. Journal of Geophysics and Engineering, 9: 428-432.

KHALEELULLA S. 1982. Counterexamples in topological vector spaces. Berlin, Springer-Verlag Berlin and Heidelberg. 2nd ed., 184 pp.

KURT H. 2007. Joint inversion of AVA data for elastic parameters by bootstrapping. Computers \& Geosciences, 33(3): 367-382.

LARSEN J. 1999. AVO Inversion by Simultaneous P-P and P-S Inversion. Master's dissertation. University of Calgary, Department of Geology and Geophysics. Calgary, Canada. 124 pp.

LI X. 2003. Converted-wave moveout analysis revisited: The search for a standard approach. In: 73rd Annual International Meeting. Expanded Abstract, p. 805-808. Dallas, Texas, USA: Society of Exploration Geophysicists.

LI X \& YUAN J. 1999. Converted-wave moveout and parameter estimation for transverse isotropy. In: 61st EAGE Conference. Volume 1 Expanded Abstract, p. 4-35. Helsinki, Finland.

LI X \& YUAN J. 2001. Converted-wave imaging in inhomogeneous, anisotropic media: Part I - Parameter estimation. In: 63rd EAGE Conference. Volume 1 Expanded Abstract, p. 109. Amsterdam, Netherlands.

MALOVICHKO A. 1978. A new representation of the traveltime curve of reflected waves in horizontally layered media. Applied Geophysics, 91(1): 47-53. [In Russian]. 
MARGRAVE GF. 2000. New seismic modelling facilities in Matlab. CREWES Research Report. 12nd ed., 45 pp.

MARGRAVE GF. 2003. Numerical Methods of Exploration Seismology with algorithms in MATLAB. Canada: The University of Calgary, Department of Geology and Geophysics. 225 pp.

MUIR F \& DELLINGER J. 1985. A practical anisotropic system. In: PROJECT SE (Ed.). SEP-44. p. 55-58.

SLOTBO0M R. 1990. Converted wave (P-SV) moveout estimation. In: 60th Annual International Meeting. Expanded Abstract, p. 1104-1106. San Francisco, CA: Society of Exploration Geophysicists.

THOMSEN L. 1986. Weak elastic anisotropy. Geophysics, 51: 1954-1966.

THORBECKE J \& DRAGANOV D. 2012. Finite-difference modeling experiment for seismic interferometry. Geophysics, 76: H1-H18.

URSIN B \& STOVAS A. 2006. Traveltime approximations for a layered transversely isotropic medium. Geophysics, 71: 23-33.

ZUNIGA N. 2017. Análise comparativa de aproximações não-hiperbólicas dos tempos de trânsito de dados sísmicos multicomponente utilizando tecnologia OBN. Master's dissertation. Universidade de São Paulo. Brazil. 86 pp.
ZUNIGA N, BOKHONOK 0 \& DIOGO L. 2015. Comparison of nonhyperbolic travel-time approximations for multicomponent seismic data. In: 14th SBGf Congress. Expanded Abstract, p. 1176-1181. Rio de Janeiro, Brazil.

ZUNIGA N, MOLINA E \& PRADO R. 2016a. Inversion of multicomponent seismic data for VTI medium using the globalized Nelder-Mead optimization algorithm. In: 3rd EAGE/SBGf Workshop. Rio de Janeiro, Brazil. Expanded Abstract.

ZUNIGA N, MOLINA E \& PRADO R. 2016b. Inversion of multicomponent seismic data of the Santos Basin. In: Far East Hydrocarbons 2016. Expanded Abstract, Yuzhno-Sakhalinsk, Russia.

ZUNIGA N, MOLINA E \& PRADO R. 2017. Comparison of travel-time approximations for unconventional reservoirs from Santos Basin, Brazil. Brazilian Journal of Geophysics, 35(4): 273-286.

ZUNIGA N, RIBEIRO F \& PRIMENKO V. 2018. Relation between the model and the topography of the objective function in a velocity analysis using a nonhyperbolic multicomponent travel-time approximation. Brazilian Journal of Geophysics, 36(4): 375-384.

Recebido em 7 de março de 2019 / Aceito em 6 de maio de 2019

Received on March 7, 2019 / Accepted on May 6, 2019 